\title{
Biosynthesis of Silver nanoparticles from aqueous extract of unripe plantain peel and its antibacterial assay: a novel biological approach
}

\author{
Iyanuoluwa Temitayo, OLUGBEMI \\ Lecturer III, Department of Science Laboratory Technology, Federal \\ Polytechnic Ilaro, Ogun State. \\ Email/Phone no; iyanugbemie@gmail.com Phone no;+2347066025250
}

\section{Abstract}

Biological method of silver nanoparticles synthesis has now become a novel method to physical and chemical approaches. In the present study, silver nanoparticles (AgNPs) were synthesized from unripe plantain peel extract (UPPE).This study examined the aqueous extracts of unripe plantain peel (sundried and air-dried) for the synthesis of Silver nanoparticles and compared their possible antibacterial potencywith standard antibiotics: Ofloxacinand Ampicillinagainst human pathogens such asEscherichia coli and Salmonellatyphi.The silver nanoparticles were prepared by reducing $\mathrm{AgNO}_{3}$ with unripe plantain peel extractwhich act as natural reducing agent. The antimicrobial assay was carried out using Mueller Hinton Agar well .Synthesis of AgNps was confirmed by UV-Visible spectroscopy and plasmon peak maxima was observed at $425 \mathrm{~nm}$ and $475 \mathrm{~nm}$ for sundried and airdried samples (SD-AgNps and $\mathrm{AD}-\mathrm{AgNps}$ ) respectively at $24 \mathrm{~h}$ interval. The antibacterial assay of the samples revealed higher antimicrobial activity for SDAgNps against Escherichia colithan Ofloxacin while ADAgNps showed antibacterial activity against E. coli and ampicillin showed none. SDAgNps showed a synergetic effect with the standard antibiotics (ofloxacin) against Salmonella typhi. Hence, the antimicrobial activities of the AgNps synthesized from aqueous extract of unripe plantain could be utilized in the management of infectious diseases due to their antimicrobial potency.

Keywords; Antimicrobial Activity,Silver nanoparticle (AgNp),Unripe Plantain Peel,UVVisible Spectroscopy

\section{INTRODUCTION}

Nanotechnology involves the synthesis, characterization, fabrication, and manipulation of devices, or materials that have at least one dimension (or contain components with at least one dimension) that is approximately $1-100 \mathrm{~nm}$ in length. Particle size below this threshold has been found to have physical and chemical properties that are significantly different from the properties of macroscale materials composed of the same substance ${ }^{1}$. In recent years the biosynthetic method of employing plant and plant waste extracts for the synthesis of metal nanoparticle has received some attention as a simple,ecofriendly and viable alternative to chemical procedures and physical ${ }^{2}$.Silver nanoparticles in comparism to other metal nanoparticles has been reported to be non-toxic to humans and most effective against bacteria $^{3}$. A very important aspect of recent nanotechnology research is the development of consistent processes for the synthesis of silver nano materials, one of which is the green synthesis ${ }^{4}$.Crude extracts from fruits could act as green reactant for silver nanoparticles synthesis $^{5}$. Extensive work has been carried out on the biological synthesis of nanoparticles 
by using plant extracts ${ }^{6,7,8}$. However very few studies are available on the biosynthesis of silver nanoparticles from peel extracts ${ }^{9,10}$.

Plants are an important source of food and energy for man. ${ }^{11}$ Musa paradisiaca whichis in the family of Musaceae, genus Musa and specie paradisiaca is a mono herbaceousperennial crop $^{12}$ that is an important staple food in Nigeria ${ }^{13}$.It has several nutritional values because it is rich in phyto-nutrients ${ }^{14}$ henceseveral delicacies are made from plantain fruits. The unripe fruits for instance are processed into flour and thickened into paste by stirring in boiling water. The ripe or unripe mature fruits canalso be consumed boiled, steamed,pounded, roasted or fried into chips while the overripe plantains are fried with palm oil ${ }^{12}$. Peel is the main by-product of the plantain processing industry and it represents about30\% of the fruit ${ }^{15}$. Because the demand for processed and unprocessed plantain fruit (ripe and unripe) in Nigeria is high,this result to abundant waste generation in the form of plantain peels thereby constituting a menace to the environment, processing industries and pollution monitoring agencies ${ }^{15,16}$. This problem can be recoveredby utilizing its high value compounds in the development of potential new drugs.However, due to poor permeability, poor solubility, low bioavailability, etc, the delivery of herbal therapeutic molecules as drugs is challenging. These limitations can be overcome by attaching or encapsulating the herbal drugs with suitable nanomaterials which can enhance their pharmacokinetics and improve their performance to a great extent ${ }^{17}$. Report has shown that unripe plantain peel contains polymers such as lignin, hemicellulose and pectins ${ }^{4}$ which can be utilized in the synthesis of silver nanoparticles. Drug resistance among human pathogens as well as undesirable side effects of certain antimicrobial agents have been reported ${ }^{18}$.Products that can prevent pathogens from growing and shows only slight toxicity on host cells are being looked at as good candidates for the development of new antimicrobial drugs ${ }^{19}$.

\section{Materials and Methods}

\subsection{Materials}

Silver nitrate $\left(\mathrm{AgNO}_{3}, 99.995 \%\right)$ was purchased from Sigma Aldrich USA. Unripe plantain was obtained from local market.

\subsection{Sample Preparation}

The unripe plantain peels were removed using table knife, and the peels were diced into small pieces and washed thoroughly with distilled water. A portion of the peels were air-dried for 1 day while the other part was sundried for 5 days. The air- dried peels were chopped into smaller pieces using a clean knife whereas the sundried peels were ground into fine powder using an automatic electric blender.

\subsubsection{Extract preparation}

Chopped Air-dried (25g) and Powdered (25g) unripe plantain peel was weighed into separate beakers containing $100 \mathrm{ml}$ distilled water. The mixtures were boiled in a water bath at $60^{\circ} \mathrm{C}$ for $30 \mathrm{~min}$.filtered and centrifuged at $1000 \mathrm{rpm}$ for $10 \mathrm{~min}^{10}$. The samples were labeled as sun-dried (SD) and air-dried(AD)and stored at $-20^{\circ} \mathrm{C}$

\subsection{Synthesis of silver nanoparticle}

Aqueous solution of $1 \mathrm{mM}$ silver nitrate $\left(\mathrm{AgNO}_{3}\right)$ was prepared and used for the synthesis of silver nanoparticles. AD (5 ml) and SD (5ml) unripe plantain peel extracts were added into 95 $\mathrm{ml}$ of aqueous solution of $1 \mathrm{mM}$ silver nitrate for reduction into $\mathrm{Ag}^{+}$and kept for incubation period of $24 \mathrm{hr}$ at room temperature. Here the filtrate acts as reducing and stabilizing agent for $1 \mathrm{mM}$ of $\mathrm{AgNO}_{3}$ to bring about the synthesis of AD-AgNps and SD-AgNpsfor air-dried and 
sun-dried nanoparticles respectively ${ }^{5}$.One tube each was kept as a control without addition of $1 \mathrm{mM} \mathrm{AgNO} 3$ solution for both extracts.

\subsection{Characterization of silver nanoparticles}

The reduction of pure $\mathrm{Ag}^{+}$ions was monitored by measuring the UV spectrum of the reaction medium after overnight incubation after diluting a small aliquot of the sample in distilled water. The silver nanoparticles synthesized were analyzed using UV-Visible spectrophotometer. The scanning range for the samples was 300-600 nm.

\subsection{Assessment of antibacterial activity of silver nanoparticles/Extracts}

Antibacterial activity of extracts and synthesized silver nanoparticles was tested against Salmonella typhimurium,Escherichia coli.

\subsubsection{Test Pathogens}

The bacterial pathogensemployed in this work were obtained from the Molecular Biology Laboratory of Covenant University after proper identification by acertified Microbiologist, the chief technologist, Mr Emmanuel Omonigbeyin.

\subsubsection{Preparation of Sample for Antimicrobial Assay}

All four (4) samples were kept in the oven at $60^{\circ} \mathrm{C}$ and allowed to dry completely ${ }^{19}$. The amounts of dried metabolites obtained from all samples were dissolved in Distilled water making extracts of different concentrations.

Table1-Different concentration of samples

\begin{tabular}{|l|l|l|l|l|l|l|}
\hline S/No & Sample & $\begin{array}{l}\text { Weight of } \\
\text { Empty } \\
\text { Bottle }+ \\
\text { Extract(g) }\end{array}$ & $\begin{array}{l}\text { Weight of } \\
\text { Empty } \\
\text { Bottle(g) }\end{array}$ & Extract(g) & $\begin{array}{l}\text { Distilled } \\
\text { water }(\mathrm{ml})\end{array}$ & $\begin{array}{l}\text { Concentration } \\
(\mathrm{mg} / \mathrm{ml})\end{array}$ \\
\hline 1 & AD & 224.60 & 224.40 & 0.20 & 15.00 & 13.33 \\
\hline 2 & SD & 213.80 & 213.60 & 0.20 & 15.00 & 13.33 \\
\hline 3 & AD-AgNps & 223.41 & 223.40 & 0.01 & 15.00 & 0.67 \\
\hline 4 & SD-AgNps & 351.81 & 351.80 & 0.01 & 15.00 & 0.67 \\
\hline
\end{tabular}

\subsubsection{Antibacterial Assay}

The antimicrobial potency of the samples was checked using Agar well diffusion method as described by Abhay et al ${ }^{10}$, with appropriate modifications. In brief, Muller Hinton agar was poured into petri dishes.After solidification of nutrient agar plates, $20 \mu \mathrm{l}$ of standardized inoculum of the test organism was seeded on respective plates and wells of $5 \mathrm{~mm}$ diameter were bored using a cork borer. About $50 \mu \mathrm{l}$ of extracts, synthesized AgNPs, a disk of standard antibiotic;Ampicillinand Ofloxacin, a quinolone $(25 \mu \mathrm{g})$ was used. Plates were incubated at 37 ${ }^{\circ} \mathrm{C}$ for $24 \mathrm{hrs}$ and was inspected for zone of inhibition.Ampicillinand Ofloxacin were used as positive controls in this experiment

\section{RESULTAND DISCUSSION}

Development of reliable and eco-friendly process for synthesis of metallic nanoparticles is an important step in the field of application of nanotechnology ${ }^{9}$.The synthesis of silver nanoparticles through unripe plantain peel was confirmed bythe color change of the solution after $24 \mathrm{hrs}$ of incubation viz., light yellow in air-dried sample and brownish-orange color in 
sundried sample (Figure 1-2). Report has shown that silver nanoparticles exhibit striking color of yellow to brown due to the excitation of surface plasmon vibration in the particlesand that the peak value between $400-500 \mathrm{~nm}$ ranges indicates the presence of silver nanoparticles by UV- Visible spectrophotometer analysis ${ }^{20}$. The peak value for SD-AgNps and AD-AgNps was found to be 427nm and 488nmrespectively as shown in (Figure 3-4).

Synthesis of nanosized particles with antibacterial properties is of great interest in the development of new pharmaceutical products ${ }^{20}$. The silver nanoparticles synthesized fromaqueous extract of unripe plantain peelshowed good antibacterial activity against the two bacterial strains used. The antibacterial activity was confirmed on the basis of zone size exhibited by standard antibacterial agent Ofloxacin and Ampicillin against E.coliandSalmonella typhi are gram -ve bacteria and are food borne pathogens. Many common bacterial infection such as cholecystitis, cholangitis ,bacteremia, urinary tract infection, traveler's diarrhea and other clinical infections such as neonatal meningitis and neumonia are caused by E.coli ${ }^{21}$. Salmonella like E.coli causes the life threatening infection called typhoid fever in humans ${ }^{22}$.Ofloxacin is a quinolone which is known to be active against gram +ve and gram -ve bacteria whereas Ampicillin is a gram-ve antibacterial agent.Reportby Abhay and Rupa ${ }^{10}$,confirmed that infectious diseases which is the leading cause of death worldwide is as a result of multidrug resistant strain of bacteria.Our findings showed thatno zone of inhibition was observed for AD and SD unripe plantain peels(normal control) against the pathogens used whereas SD-AgNps had a zone of inhibition of $13 \mathrm{mmand} 15 \mathrm{~mm}$ against E.coliandSalmonella typhi respectively while Ofloxacin had a zone of inhibition of $10 \mathrm{~mm}$ and $22 \mathrm{mmagainst}$ E.coliandSalmonella typhi respectively.The result also revealeda synergetic effect between SD-AgNps and the standard antibiotics (Ofloxacin) showing a zone of inhibition of $44 \mathrm{~mm}$ against Salmonella typhi. Ampicillin did not inhibit the growth of E.coli whereas the AD-AgNps had a zone of inhibition of $12 \mathrm{~mm}$ against E.Coli (Figure 5). This resultconfirmed the report by kim et al., ${ }^{23}$ that AgNPs has a broad antibacterial effect on a range of Gram-negative and Gram-positive bacteria and antibioticresistant bacteria strains.

a)

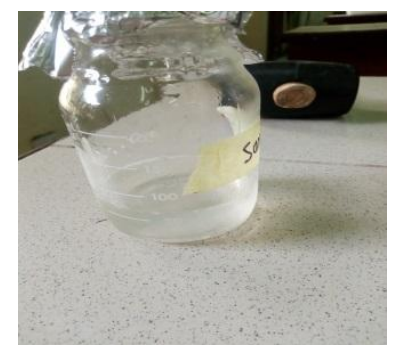

b)

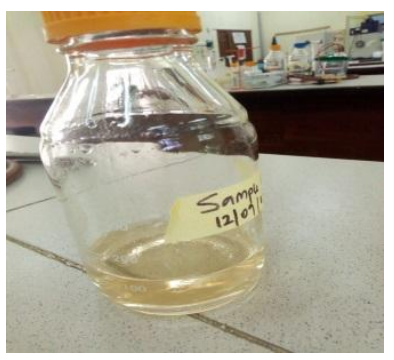

Figure 1- a) Clear Aqueous extracts of airdried unripe plantain peel extract (AD) and b)Solution of synthesized air-dried unripe plantain peel nanoparticle (AD-AgNps)

a)

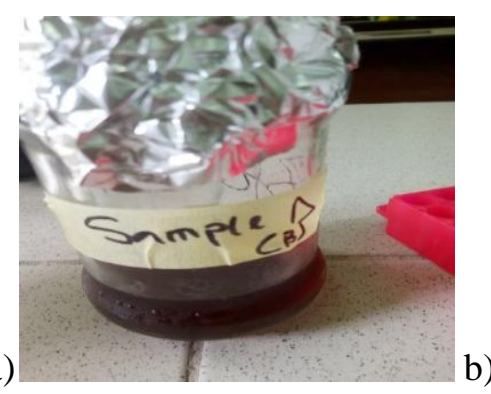

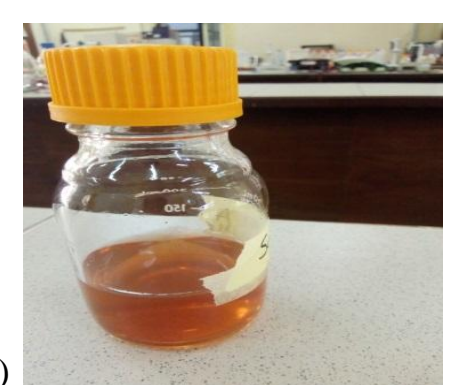

Figure 2- a) Clear Aqueous extract of sundried unripe plantain peel extract (SD) (b) Solution of synthesized sun dried unripe plantain peel nanoparticle (SD-AgNps) 
Figure 3:UV-Vis Characterization of AgNPs:airdried unripe plantain peel extract

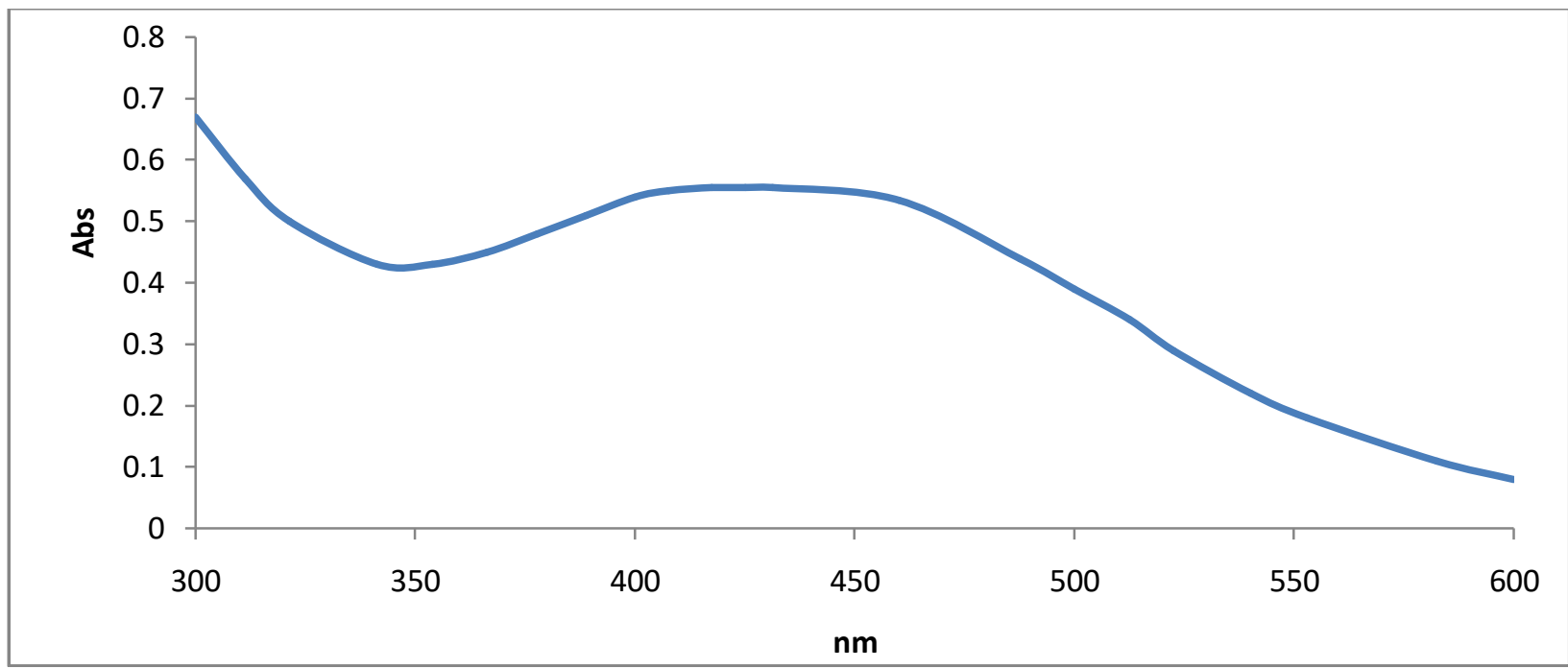

Figure 4:UV-Vis Characterization of AgNPs :sundried unripe plantain peel extract

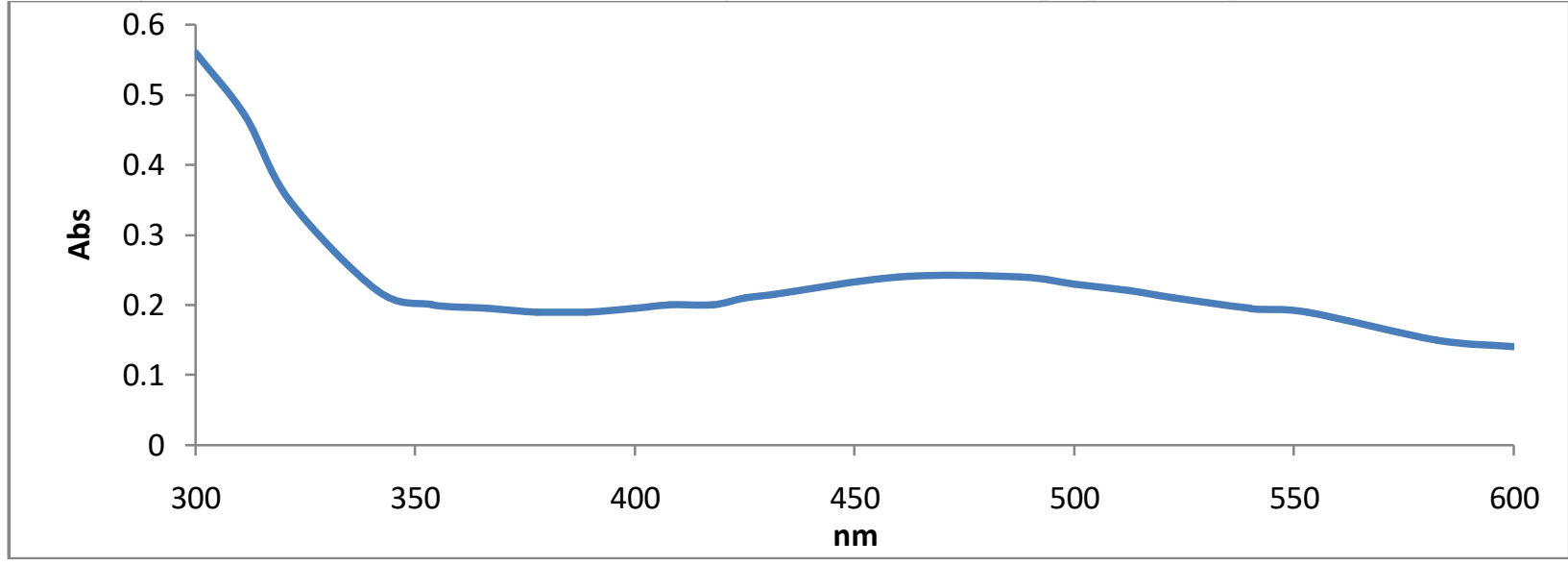

Figure 5: Zone of inhibition of samples

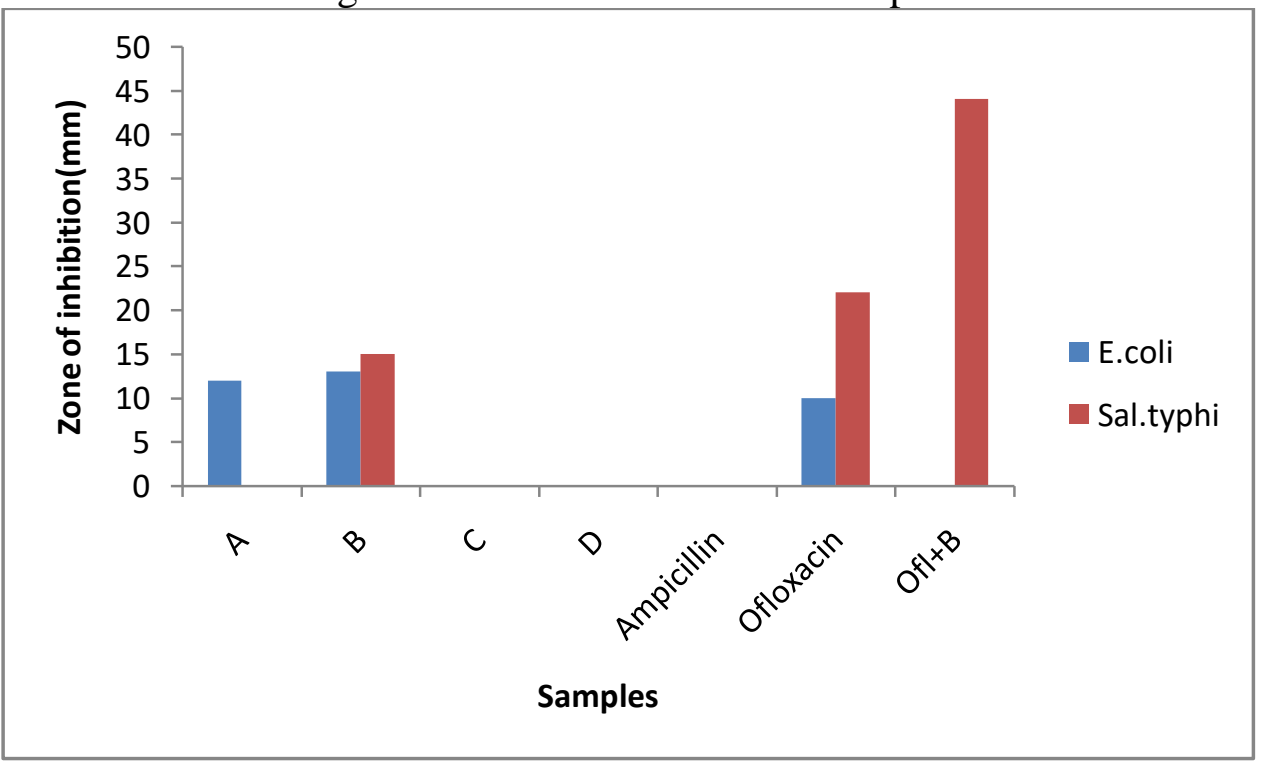

A-AgNps; Airdried unripe plantain peel extract, C-Airdried Sample extract B-AgNps; Sundried unripe plantain peel extract, D-Sundried sample extract 


\section{CONCLUSION}

The present study is an initial work on the biosynthesis of silver nanoparticles from aqueous extracts of airdried and sundried unripe plantain peel. Based on the above research work it can be concluded that AgNps synthesized from aqueous extract of unripe plantain peel could be used as an effective drug against pathogenic diseases after proper pharmacological evaluation.

\section{ACKNOWLEDGEMENT}

I acknowledge the assistance of Mr Omonigbeyin, Chief Technologist, Molecular Biology Laboratory, Covenant University for the microbial analysis.

\section{REFERENCES}

1. Duncan T.V. Applications of nanotechnology in food packaging and food safety: Barrier materials, antimicrobials and sensors. Journal of Colloid Interface Science., 2011; 363:124.

2. Suganya T.R and Devasena T. Exploring the mechanism of anti-inflammatory activity of phyto-stabilized silver nanorods.Journal of Nanomaterials and Biostructures., 2015;10:277-282.

3. Jeong S.H, Yeo, S.Y and Yi, S.C. The effect of filler particle size on the antibacterial properties of compounded polymer/silver fibers. Journal of Material Science., 2005;40:5407-5411.

4. Agama-Acevedo J.A, Sañudo-Barajas R, Vélez De La Rocha G.A, González-Aguilar and Bello-Peréz, L.A. Potential of plantain peels flour (Musaparadisiaca L.) as a source of dietary fiber and antioxidant compound, CyTA. Journal of Food., 2016; 14(1): 117-123.

5. Calzada F, Yépez-Mulia L and Tapia-Contreras, A. Effect of Mexican medicinal plant used to treat trichomoniasis on Trichomonas vaginalis trophozoites. Journal of Ethnopharmacology., 2007; 113:248-225.

6. Shankar S, Ahmad A and Sastry. Geranium leaf assisted biosynthesis of silver nanoparticles. Biotechnology Progress., 2003;19:1627-1631.

7. Subbaiya R, Shiyamala M, Revathi K, Pushpalatha, R and Masilamani, S.M. Biological synthesis of silver nanoparticles from Nerium oleander and its antibacterial and antioxidant property. International Journal of Current Microbiology and Applied Sciences., 2014;3(1):83-87.

8. Prathibha S, Packiyam J.E, Bhat P.R, Jayadev K and Shetty S. Green synthesis of silver nanoparticles from fruit extracts of Terminalia chebula Retz. and their antibacterial activity. International Journal of Research in Biosciences., 2015; 4(2):29-35.

9. Kirubha $\mathrm{R}$ and Alagumuthu G. Investigation of antibacterial properties of silver nanoparticles using Aerva lanata extract. Indo American Journal of Pharmaceutical Sciences., 2015; 2(3):668-675.

10. Abhay $\mathrm{T}$ and Rupa $\mathrm{S}$. Antimicrobial activities of silver nanoparticles synthesized from peel of fruits and vegetables. Journal of Biological Innovations Research and Development Society., 2016;1: 29-34.

11. Ajanaku C.O, Echeme J.O, Mordi R.C, Ajani O.O, Olugbuyiro J.A.O, Owoeye T.F, Taiwo O.S and Ataboh J.U. Phtochemical screening and Antimicrobial studies of CratevaadansoniiLeaf Extract. Covenant Journal of Physical \& Life Sciences., 2016; 4(2):35-41.

12. Makanjuola O.M, Ajayi A, Bolade M.Kand Makanjuola J. The proximate compositionand mineral contents of three plantaincultivars harvested at matured green level.International Journal of Innovations in Bio-Sciences., 2013; 3(2):23-26. 
13. Adeolu A.T and Enesi D.O. Assessment ofproximate, mineral, vitamin and phytochemical compositions of plantain(Musa paradisiaca) bract - an agricultural waste. International Research Journal of Plant Science., 2013; 4(7):192-197.

14. Happi E.T, Bindelle J, Agneesens R., Buldgen A, Wathelet B and Paquot M. Ripening influences banana and plantain peels composition and energy content. Trop. Anim. Health Prod.2011; 43(1):171-177.

15. Arun K.B, Persia F, Aswathy P.S, Chandran J, Sajeev M.S, Jayamurthy P and Nisha P. Plantain peel - a potential source of antioxidant dietary fibre for developing functional cookies. J Food Sci Technol., 2015;15:1727-1730.

16. Egbuonu A.C, Ogele O.M and Amaraihu K.L. Comparative Evaluation of the Proximate Composition and Antibacterial Activity of Ground Musa paradisiaca (Plantain) Peels and Leaves.British Biotechnology Journal., 2016: 15(2): 1-9.

17. Okafor F, Janen A, Kukhtareva T, Edwards V and Curley M. Green synthesis of silver nanoparticles, their characterization, application and antibacterial activity. Int $\mathrm{J}$ Environ Res Public Health., 2013; 10:5221-5225.

18. Olasehinde G.I, Sholatan K.J, Openibo J.O, Taiwo O.S. Bello O.A, Ajayi J.B, Ayepola O.O and Ajayi A.A. Phytochemical and Antimicrobial Properties of Mangifera indica Leave Extracts.Covenant Journal of Physical \& Life Sciences., 2018; 6(1):55-63

19. Sengul M, Ercisl Sezai, Yildiz H, Gungor N, Kavaz Aand Çetin B.Antioxidant, Antimicrobial Activity and Total Phenolic Content within the Aerial Parts of Artemisia absinthum, Artemisia santonicum and Saponaria officinalis.Iranian Journal of Pharmaceutical Research., 2011; 10 (1): 49-56.

20. Gloria A.O, Anthony J.A, Emmanuel O.A and Samuel W.O. Characterization, antibacterial and antioxidant properties of silver nanoparticles synthesized from aqueous extracts of Allium sativum, Zingiber officinale, and Capsicum frutescens. Pharmacognosy Magazine., 2017; 13(50):201-208.

21. Reenaa, M., and Menon, A.S. 2017.Synthesis of Silver Nanoparticles from Different Citrus Fruit Peel Extracts and a Comparative Analysis on its Antibacterial Activity. International Journal of Current Microbiology and Applied Sciences.6(7): 2358-2365.

22. Tarun M,Chi Hiong, U.G, Charles V.S (2019). Escherichia coli (E.Coli)infections. Medscape.https://emedicine.medscape.com/article/217485.

23. World Health Organization.2018. Key facts about typhoid fever.https://www.who.int/news-room/fact-sheets/detail/typhoid.

24. Kim, J.S., Kuk, E., Yu, K.N., Kim, J.H., Park, S.J., Lee, H.J., Kim, S.H., Park, Y.K., Park, Y.H., Hwang, C.Y., Kim, Y.K., Lee, Y.S., Jeong, D.H. and Cho, M.H. (2007). Antimicrobial effects of silver nanoparticles. Nanomedicine, 3(1):95-101. 